\title{
PROLONGED POST - OPERATIVE HOSPITALIZATION PREDICTS HIGH BURDEN OF UMBLICAL PORT SITE INFECTION IN LAPAROSCOPIC CHOLECYSTECTOMY.
}

\author{
DR. ABDUL HADI, MBBS. \\ Nishtar Hospital, Multan, Pakistan. \\ DR. MUHAMMAD TAHA BIN AQEEL, MBBS. \\ Nishtar Hospital, Multan, Pakistan. \\ DR. MUHAMMAD SHAHBAZ, MBBS. \\ Nishtar Hospital, Multan, Pakistan.
}

\begin{abstract}
;
Background; Laparoscopic cholecystectomy is one of the commonly performed surgical procedure these days which is associated with significant reduction of morbidities and mortality. This study was conducted to ascertain port site infection after laparoscopic cholecystectomy without using gloves. Objective; To determine frequency of port site infection (PSI) in patients undergoing laparoscopic cholecystectomy when gallbladder is removed without using gloves. Material and Methods; A total of 254 patients undergoing laparoscpic cholecystectomy were enrolled in our study. The laparoscopic cholecystectomy was performed and after removal of gall bladder without endogloves the laparoscope was moved to the epigastric port, and a large-tooth grasping forceps were inserted through the umbilical port to grasp the gallbladder at the area of the cystic duct and were followed for wound infection. Results; Of these 254 study cases, 98 (36.6 \%) were male patients while 156 $(61.4 \%)$ were female patients. Mean age of our study cases was $49.58 \pm 6.32$ years. Of these 254 study cases, 89 (35.0 \%) belonged to rural areas and $165(65.0 \%)$ belonged to urban areas. Diabetes was present in $68(26.8 \%)$ of our study cases. Hypertension was present in 126 (49.6\%) of our study cases. Mean duration of surgery was $55.28 \pm 15.23$ minutes and $185(72.8 \%)$ had duration of procedure up to 1 hour. Mean hospital stay was $5.22 \pm$ 2.18 days and $204(80.3 \%)$ had hospital stay up to 6 days. Umblical port site infection (PSI) was noted in 20 (7.9\%). Conclusion; High frequency of umblical port site infection was noted in our study among patients undergoing laparoscopic cholecystectomy without using gloves, so use of gloves is safe, cost effective and reduces related morbidities. Port site infection was significantly associated with increasing, gender, diabetes, residential status, prolonged duration of surgery and duration of hospitalization.
\end{abstract}

Keywords; Umblical Port site infection, gloves, Laparoscopic cholecystectomy

DOI: $10.7176 / \mathrm{JMPB} / 54-13$

Publication date: April $30^{\text {th }} 2019$

\section{INTRODUCTION;}

Gallstone disease is the most common global indication for abdominal surgery. The prevalence of gallstones increases with age in both sexes and in nearly all populations. Since the introduction of laparoscopic cholecystectomy (LC) nearly two decades ago, and the more recent use of it as an outpatient procedure, many surgeons now view cholecystectomy as a relatively simple procedure from which patients recover quickly ${ }^{1}$. Laparoscopic cholecystectomy (LC) is one of the most commonly performed operation in surgical practice ${ }^{2-4}$. It has generally accepted advantages, like a more comfortable, less painful postoperative period and a more rapid return to normal activities. Safe dissection is most important component of successful LC ${ }^{2-4}$. Despite 
remarkable advances in the use of surgical techniques and prophylactic antibiotics and environmental/ergonomic improvements in the operating room, surgical site infections (SSIs) remain a significant cause of patient morbidity and mortality and are the third-most common source of hospital-acquired infection. Of concern is that SSIs occur in up to $30 \%$ of all surgical procedures, and yet most are preventable ${ }^{5,6}$.

Port site infection (PSI), although infrequent, is one of the bothersome complications which undermine the benefits of minimal invasive surgery. Not only does it add to the morbidity of the patient but also spoils the reputation of the surgeon. Despite the advances in the field of antimicrobial agents, sterilization techniques, surgical techniques, operating room ventilation, PSIs still prevail. The emergence of rapid growing atypical mycobacteria with multidrug resistance, which are the causative organism in most of the cases, has further compounded the problem. PSIs are preventable if appropriate measures are taken preoperatively, intraoperatively and postoperatively. PSIs can often be treated non-surgically, with early identification and appropriate management. Macrolides, quinolones and aminoglycosides antibiotics do show promising activity against the atypical mycobacteria ${ }^{7}$.

There are number of factors contributing to the development of postoperative wound infections. Attempts have been made to control these by variety of methods. However there is misplaced belief that antibiotics are solution to all of these, thus leading to their inappropriate use and resultant emergence of the resistant microorganisms ${ }^{8}$. Taj et al ${ }^{8}$ reported $5.28 \%$ PSI without using gloves in patients undergoing laparoscopic cholecystectomy while with gloves PSI was $0.20 \%{ }^{8}$.

The aim of this study was to assess PSI in patients undergoing laparoscopic cholecystectomy without using gloves. It will help to take more preventive measures by surgical team to decrease these infections which are associated with increased morbidity, prolonged hospitalizations, mortality and increased hospital costs.

\section{MATERIAL AND METHODS;}

Consecutive 254 patients undergoing laparoscopic cholecystectomy were taken. Patients meeting inclusion criteria was enrolled in this study from department of surgery, Nishtar Hospital Multan. Severely anemic patients, Chronic liver disease, Alcoholic abuse and pregnant ladies were excluded from our study. Informed consent was taken from each patient describing them objectives of this study, ensuring them confidentiality of the information and fact that there is no risk involved to the patient while taking part in this study. All baseline investigations like blood tests (FBS, RBS and Hb levels) and ultrasonography were done at hospital facility free of cost. The laparoscopic cholecystectomy was performed by a senior same surgeon having more than 5 years of experience after fellowship and after removal of gall bladder without endo-gloves the laparoscope was moved to the epigastric port, and a large-tooth grasping forceps was inserted through the umbilical port to grasp the gallbladder at the area of the cystic duct. Under direct vision, the gallbladder was then retrieved and pulled out as far as possible through the umbilical port and was followed till 30 days to document Port Site Infections. All the data was entered and analyzed using SPSS-20. Mean and standard deviation for the post-operative hospital stay and age was calculated. Frequencies and percentage were calculated for the categorical variables like gender, diabetes, hypertension, age groups, PSI (Yes/No), obesity (Yes/No) and residential status.

\section{$\underline{\text { RESULTS; }}$}

Our study comprised of a total of 254 patients meeting inclusion criteria of our study. Of these 254 study cases, $98(36.6 \%)$ were male patients while $156(61.4 \%)$ were female patients. Mean age of our study cases was 49.58 \pm 6.32 years (with minimum age of our study cases was 39 years while maximum age was 60 years). Mean age of the male patients was noted to be $48.71 \pm 5.01$ years while that female patients was $50.13 \pm 6.98$ years $(\mathrm{p}=0.083)$. Our study results have indicated that majority of our study cases i.e. $155(61 \%)$ were aged more than 45 years. Of these 254 study cases, $89(35.0 \%)$ belonged to rural areas and $165(65.0 \%)$ belonged to urban areas. Diabetes was present in $68(26.8 \%)$ of our study cases. Hypertension was present in $126(49.6 \%)$ of our study cases. Mean body mass index of our study cases was $26.21 \pm 1.82 \mathrm{~kg} / \mathrm{m}^{2}$ and obesity was present in 78 $(30.7 \%)$ of our study cases. Mean duration of surgery was $55.28 \pm 15.23$ minutes and $185(72.8 \%)$ had duration of procedure up to 1 hour. Mean hospital stay was $5.22 \pm 2.18$ days and $204(80.3 \%)$ had hospital stay up to 6 days. Umblical port site infection (PSI) was noted in $20(7.9 \%)$ of our study cases. 
Table No. 1 Stratification of Port site infection with regards to hospital stay.

$$
(n=254)
$$

\begin{tabular}{|c|c|c|c|}
\hline \multirow[b]{2}{*}{ Hospitalization } & \multicolumn{2}{|c|}{ Port site infection } & \multirow[b]{2}{*}{$P$ - value } \\
\hline & $\begin{array}{c}\text { Yes } \\
(\mathrm{n}=20)\end{array}$ & $\begin{array}{c}\text { No } \\
(\mathrm{n}=234)\end{array}$ & \\
\hline $\begin{array}{l}\text { Up to } 6 \text { days } \\
(\mathrm{n}=204)\end{array}$ & 05 & 199 & \multirow{3}{*}{0.000} \\
\hline $\begin{array}{c}\text { More than } 6 \text { days } \\
(\mathrm{n}=50)\end{array}$ & 15 & 35 & \\
\hline Total & \multicolumn{2}{|c|}{254} & \\
\hline
\end{tabular}

\section{DISCUSSION;}

Gall stone disease is one of the most common digestive tract diseases and constitutes an important health problem in developed countries. About 750,000 patients undergo cholecystectomy per year in the United States, and the number of surgical procedures has grown increasingly over the years, with the purpose to avoid the symptoms, complications and recurrence of gallstones in the biliary tract. The introduction of the laparoscopic technique in 1985, first made by Mühe was an important factor for the large increase in the cholecystectomy, since it represented a less invasive technique, generated better esthetic result and provided a lower surgical risk compared to the conventional procedure. Dubois and Barthelot introduced in 1982, minimally invasive technique for conventional cholecystectomy, the minilaparotomy cholecystectomy and Tyagi et al, in 1994, described a new technique for minimally invasive cholecystectomy, and this has recently challenged the role of laparoscopic cholecystectomy ${ }^{9,10}$.

Our study comprised of a total of 254 patients meeting inclusion criteria of our study. Of these 254 study cases, $98(36.6 \%)$ were male patients while $156(61.4 \%)$ were female patients. A study conducted by Channa et al ${ }^{11}$ from Jamshoro also reported high female gender predominance with male to female ratio was 1:3 which is in compliance with that of our study results. Samad et al ${ }^{12}$ from Hyderabad also reported $87 \%$ female gender preponderance which is in compliance with our study results. A Study conducted by Rahman et al ${ }^{13}$ from Peshawar also reported male to female ratio was 1:2 which is in compliance with our study results. Sattar et al ${ }^{14}$ from Karachi also reported $73 \%$ female gender predominance in patients with cholelithiasis which is in compliance with our study results.

Mean age of our study cases was $49.58 \pm 6.32$ years (with minimum age of our study cases was 39 years while maximum age was 60 years). Mean age of the male patients was noted to be $48.71 \pm 5.01$ years while that female patients was $50.13 \pm 6.98$ years $(\mathrm{p}=0.083)$. Our study results have indicated that majority of our study cases i.e. $155(61 \%)$ were aged more than 45 years. A study conducted by Channa et al ${ }^{11}$ from Jamshoro also reported similar results. Samad et al ${ }^{12}$ from Hyderabad also reported 54.8 years mean age of the patients which is in compliance with our study results. A Study conducted by Rahman et al ${ }^{13}$ from Peshawar also reported 55 years mean of the patients which is close to our study results. Sattar et al ${ }^{14}$ from Karachi also reported 48 years mean age which is close to our study results.

Of these 254 study cases, $89(35.0 \%)$ belonged to rural areas and $165(65.0 \%)$ belonged to urban areas. Diabetes was present in $68(26.8 \%)$ of our study cases. Hypertension was present in $126(49.6 \%)$ of our study cases. Mean body mass index of our study cases was $26.21 \pm 1.82 \mathrm{~kg} / \mathrm{m}^{2}$ and obesity was present in $78(30.7 \%)$ of our study cases. Mean hospital stay was $5.22 \pm 2.18$ days and $204(80.3 \%)$ had hospital stay up to 6 days. Ozkardeş et al ${ }^{15}$ reported mean post - operative hospital stay to be $5.2 \pm 1.40$ days in patients with laparoscopic cholecystectomy which is close to our study results. Gutt et al ${ }^{16}$ reported Mean length of hospital stay 5.4 days in patients with laparoscopic cholecystectomy which is in compliance with our study results. Jamil et al 17 reported mean hospital stay was $3.47 \pm 1.40$ days which is slightly less than that being reported in our study.

Mean duration of surgery was $55.28 \pm 15.23$ minutes and $185(72.8 \%)$ had duration of procedure up to 1 hour. Khan et al ${ }^{17}$ from Peshawar also reported 55 minutes mean duration of surgery in laparoscopic cholecystectomy which is close to our study results. Ozkardeş et al ${ }^{15}$ reported operative time in laparoscopic cholelcystectomy was $67 \pm 28.515$ (min) which is close to our study results. 
Umblical port site infection (PSI) was noted in 20 (7.9\%) of our study cases. Taj et al ${ }^{8}$ reported $5.28 \%$ PSI without using gloves in patients undergoing laparoscopic cholecystectomy which is close to our study results.

\section{CONCLUSION;}

High frequency of umblical port site infection was noted in our study among patients undergoing laparoscopic cholecystectomy without using gloves, so use of gloves is safe, cost effective and reduces related morbidities. Port site infection was significantly associated with increasing, gender, diabetes, residential status, prolonged duration of surgery and duration of hospitalization.

\section{REFERENCES;}

1. Lee $\mathrm{SI}^{1}, \mathrm{Na} \mathrm{BG}^{1}$, Yoo $\mathrm{YS}^{1}$, Mun $\mathrm{SP}^{1}$, Choi $\mathrm{NK}^{1}$. Clinical outcome for laparoscopic cholecystectomy in extremely elderly patients. Ann Surg Treat Res. 2015 Mar;88(3):145-51.

2. Bat $\mathrm{O}^{1}$. The analysis of 146 patients with difficult laparoscopic cholecystectomy. Int J Clin Exp Med. 2015 Sep 15;8(9):16127-31.

3. Henneman $\mathrm{D}^{1}$, da Costa DW, Vrouenraets BC, van Wagensveld BA, Lagarde SM. Laparoscopic partial cholecystectomy for the difficult gallbladder: a systematic review. Surg Endosc. 2013 Feb;27(2):351-8.

4. Zafar $\mathrm{SN}^{1}$, Obirieze $\mathrm{A}^{1}$, Adesibikan $\mathrm{B}^{2}$, Cornwell EE 3rd ${ }^{1}$, Fullum $\mathrm{TM}^{1}$, Tran $\mathrm{DD}^{1}$. Optimal time for early laparoscopic cholecystectomy for acute cholecystitis. JAMA Surg. 2015 Feb;150(2):129-36.

5. Leaper $\mathrm{D}^{1}$, Ousey K. Evidence update on prevention of surgical site infection. Curr Opin Infect Dis. 2015 Apr;28(2):158-63.

6. Anderson DJ, Podgorny K, Berríos-Torres SI, Bratzler DW, Dellinger EP, Greene L, et al. Strategies to prevent surgical site infections in acute care hospitals: 2014 update. Infect Control Hosp Epidemiol. 2014;35(6):605-27.

7. Sasmal PK, Mishra TS, Rath S, Meher S, Mohapatra D. Port site infection in laparoscopic surgery: a review of its management. World J Clin Cases. 2015;3(10):864-71.

8. Taj MN, Iqbal Y, Akbar Z. Frequency and prevention of laparoscopic port site infection. J Ayub Med Coll Abbottabad. 2012 Jul-Dec;24(3-4):197-9.

9. Zhou $\mathrm{MW}^{1}, \mathrm{Gu} \mathrm{XD}^{1}$, Xiang JB${ }^{1}$, Chen $\mathrm{ZY}^{1}$. Comparison of clinical safety and outcomes of early versus delayed laparoscopic cholecystectomy for acute cholecystitis: a meta-analysis. Sci World J. 2014;2014:274516. doi: 10.1155/2014/274516.

10. Castro PM, Akerman D, Munhoz CB, Sacramento Id, Mazzurana M, Alvarez GA. Laparoscopic cholecystectomy versus minilaparotomy in cholelithiasis: systematic review and meta-analysis. Arq Bras Cir Dig. 2014 Apr-Jun;27(2):148-53.

11. Channa NA, Khand FD, Bhanger MI, Leghari MH. Surgical incidence of Cholelithiasis in Hyderabad and adjoining areas (Pakistan). Pak J Med Sci. 2004;20(1):13-7.

12. Samad A. Gall bladder carcinoma in patients undergoing Cholecystectomy for Cholelithiasis. J Pak Med Assoc. 2005;55(11):497-9.

13. Rahman A, Shah SMA, Khan N, Arif A, Asadullah, Sadiq MU. Frequency of Carcinoma Gallbladder in patients undergoing surgery for chronic Cholecystitis with Cholelithiasis. J Med Sci. 2006;14(1):26-9.

14. Sattar I, Aziz A, Rasul S, Mehmood Z, Khan A. Frequency of infection in Cholelithiasis. J Coll Physicians Surg Pak. 2007;17(1):48-50.

15. Özkardeş AP, Tokaç M, Dumlu EG, Bozkurt B, Çiftçi AB, Yetişir F, et al. Early versus delayed laparoscopic cholecystectomy for acute cholecystitis: a prospective, randomized study. Int Surg. 2014 Jan-Feb;99(1):56-61.

16. Gutt CN, Encke J, Köninger J, Harnoss JC, Weigand K, Kipfmüller K, et al. Acute cholecystitis: early versus delayed cholecystectomy, a multicenter randomized trial (ACDC study, NCT00447304). Ann Surg. 2013 Sep;258(3):385-93.

17. Jamil M, Niaz K, Chaudry TH, Ali A, Saeed S. Laparoscopic cholecystectomy for acute cholecystitis: early versus delayed. Rawal Med J 2014;39(2):199-202. 
18. Khan S, Shabbir M, Oonwala ZG. Is laparoscopic cholecystectomy treatment of choice in acute cholecystitis? J Surg Pak. 2007;12(2):77-9. 